\title{
Fingolimod Hydrochloride Gel for Dermatological Applications: Optimization of Formulation Strength and Effect of Colloidal Oatmeal (Aveeno®) as Penetration Enhancer
}

\author{
M. Tamakuwala ${ }^{1}$ and G. Stagni ${ }^{1,2}$
}

Received 7 July 2015; accepted 16 September 2015; published online 29 September 2015

\begin{abstract}
Fingolimod (FNGL) is an immune-modulatory agent prescribed for relapsing forms of multiple sclerosis. Because of its mechanism of action, FNGL is potentially a treatment for chronic, non-curable Tlymphocyte-driven inflammatory skin diseases (TLDISD) such as psoriasis and atopic dermatitis. Since severe side effects limit the systemic administration of FNGL, the objective of this study is to develop a hydroxypropyl cellulose $(2 \%)$ FNGL gel for dermatological applications. First, the effect of FNGL strength $(0.05 \%, 0.10 \%, 0.50 \%$, and $1.00 \%)$ on skin permeability and retention was investigated. We carried out several permeation studies with vertical Franz diffusion cells and (i) cellulose or (ii) excised dorsal porcine ear skin (EDPES) as membrane. We also quantified FNGL in the stratum corneum and in dermis with the tape-stripping method. Permeability parameters as well as the amount retained in skin increased significantly $(p<0.01)$ with strength; however, there was no statistically significant difference between the $0.50 \%$ and $1.00 \%$ gels for both cellulose and EDPES. Therefore, we selected the $0.50 \%$ gel to investigate the effect of colloidal oatmeal $(0 \%, 1 \%, 3 \%, 6 \%$, and $10 \%)$ on FNGL in vitro permeability and skin retention. Colloidal oatmeal has beneficial dermatological properties for TLDISD and may complement FNGL activity. Permeability increased significantly $(p<0.001)$ with colloidal oatmeal at the $6 \%$ and $10 \%$ strength with an enhancement ratio of 3.5 and 2.4 , respectively, whereas the amount retained in the skin decreased significantly $(p<0.001)$ compared to the base gel. In conclusion, the $0.50 \%$ FNGL HCL gel with $6 \%$ Aveeno® has very promising permeability characteristics for delivery of FNGL to the skin.
\end{abstract}

KEY WORDS: colloidal oatmeal (Aveeno $\left.{ }^{\circledR}\right)$; fingolimod; gel topical formulation; in vitro release; skin permeability.

\section{INTRODUCTION}

T-lymphocyte-driven inflammatory skin disease (TLDISD) such as psoriasis and atopic dermatitis (AD) are chronic, non-curable ailments of the skin (1) that affect several millions of patients worldwide $(2,3)$. Topical corticosteroids (TCS) are usually the first line of defense in treating TLDISD (4). However, TCS only suppress symptoms and do not cure the disease (5). In addition, long term use of TCS is associated with several cutaneous side effects (6) that lead many patients to stop taking their medication (7). Therefore, much research effort is currently focused on exploring alternative approaches that are safer, more effective, and allow for longer remission periods. In particular, the discovery of the relationship between most chronic inflammatory skin disorders and $\mathrm{T}$ cell pathogenesis has prompted the investigation of immunemodulatory compounds as possible therapeutic agents for these diseases $(8,9)$.

\footnotetext{
${ }^{1}$ Division of Pharmaceutical Sciences, Arnold and Marie Schwartz College of Pharmacy and Health Sciences, Long Island University, 75 DeKalb Ave., Brooklyn, New York 11201, USA.

${ }^{2}$ To whom correspondence should be addressed. (e-mail: gstagni@liu.edu)
}

Fingolimod (FNGL, Fig. 1) is a structural analog of sphingosine and a non-selective sphingosine-1-phosphate receptor $\left(\mathrm{S}_{1} \mathrm{PR}\right)$ agonist $\left(\mathrm{S}_{1} \mathrm{P}_{1}-\mathrm{S}_{1} \mathrm{P}_{5}\right.$ except $\left.\mathrm{S}_{1} \mathrm{P}_{2}\right)$ currently approved for relapsing forms of multiple sclerosis (10) (0.5 $\mathrm{mg}$ capsule once every $24 \mathrm{~h}$ ). Because of its immune-modulatory properties, FNGL also has potential for the treatment of TLDISD. Indeed, FNGL in the skin may inhibit the ability of dendritic cells to migrate to draining-lymph-nodes and present antigens to naïve lymphocytes, leading to the anti-inflammatory action $(1,11)$. FNGL may also inhibit keratinocytes proliferation (12). Systemic administration of FNGL has so far been limited because of its narrow therapeutic index and severe adverse effects, in particular bradycardia, infection, and macular edema $(13,14)$. Topical delivery of $\mathrm{S}_{1} \mathrm{P}$ and FNGL as methanol solutions showed promising results in an animal model of psoriasis lesions $(11,15)$. Nakashima et al. (16) hypothesized that topical administration of FNGL might even be superior to systemic administration of FNGL in the treatment of TLDISD.

The objective of this study is to develop an optimal fingolimod gel for topical dermatological applications. We selected a gel formulation because its contact time on skin is much longer than that of a methanol solution; moreover, it is generally well accepted by patients (17). 


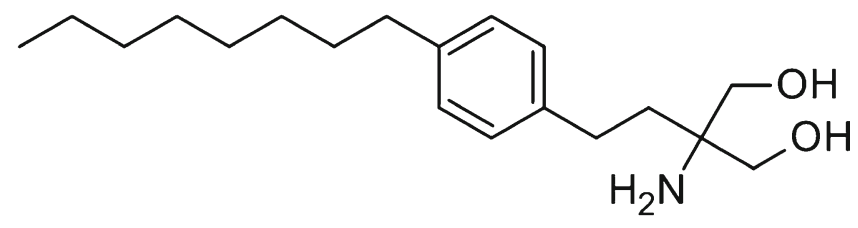

Fig. 1. Fingolimod chemical structure

Specifically, we first investigated the effect of FNGL concentration on the permeation and retention of FNGL across cellulose membrane and EDPES. Then, we studied the effect of several percentages of colloidal oatmeal (Aveeno®) on the skin permeability and retention of FNGL. Colloidal oatmeal is a natural product with a long history of beneficial effects in dermatology (18). Therefore, it may add advantageous synergistic effects to the FNGL dermatological gel in vivo, such as reduced dosage of FNGL and improved healing rate. In addition, some of the components of colloidal oatmeal, i.e., polysaccharides, proteins, lipids, saponins, enzymes, or vitamins (19), have known penetration-enhancing capability $(20,21)$. Therefore, colloidal oatmeal is an ideal candidate to be used in topical gels for patients with TLDISD because it may promote skin repair on its own and enhance drug penetration $(22,23)$.

\section{MATERIALS AND METHODS}

\section{Chemicals}

Fingolimod hydrochloride (FNGL·HCL) was purchased from LC Laboratories (Woburn, MA, USA). Spectra/Por®7 regenerated cellulose membranes from Spectrum laboratories, Inc., (Laguna Hills, CA, USA). Dulbecco's phosphate buffered saline (DPBS), bovine serum albumin (BSA), 9Fluorenylmethyl chloroformate (Fmoc- $\mathrm{Cl})$, calcium chloride, magnesium chloride, 1, 4-dioxane (dioxane), and potassium chloride were from Sigma-Aldrich (St. Louis, MO, USA). HPLC grade acetonitrile, alcohol-anhydrous (ethanol), and methanol were from J.T. Baker (Phillipsburg, NJ, USA). Sodium chloride was from EM Science (Gibbstown, NJ, USA). Hydroxypropyl cellulose (Klucel®) was from Hercules Inc. (Wilmington, DE, USA). Potassium phosphate monobasic and sodium phosphate dibasic anhydrous were from $\mathrm{VWR}^{\mathrm{TM}}$ International (West Chester, PA, USA). Colloidal oatmeal fine powder $($ Aveeno $囚)$ was purchased from a local pharmacy store.

\section{Fingolimod Hydrochloride Gel Formulation}

Klucel® $(2 \%)$ gels were prepared in batches of $20 \mathrm{~g}$ each. We weighted accurately the appropriate amount of FNGL HCL to obtain final concentrations of $0.05 \%, 0.10 \%$ , $0.5 \%$, or $1.0 \% \mathrm{w} / \mathrm{w}$; dissolved it in $5.07 \mathrm{ml}$ (equivalent to $4 \mathrm{~g}$ ) of HPLC grade ethanol and brought to final weight by addition of distilled water. The mixture was continuously stirred for 10 min using a magnetic stirrer (Corning®PC-220, Pittsburgh, PA, USA). Finally, $0.40 \mathrm{~g}$ of hydroxypropyl cellulose (HPC) was added to the resulting mixture and stirred continuously until the formation of a homogeneous clear gel. The gels were left overnight at room temperature $\left(25^{\circ} \mathrm{C}\right)$ before use. For the formulations containing Aveeno $₫$, the accurately weighed amount of Aveeno ${ }^{\circledR}$ to obtain final concentrations of
$1.0 \%, 3.0 \%, 6.0 \%$, or $10 \% \mathrm{w} / \mathrm{w}$ was added before the HPC and stirred. The $\mathrm{pH}$ of gels was in the range of 5.02-5.73 with no adjustment (Thermo Scientific ${ }^{\circledR}$ Orion 2-star $\mathrm{pH}$ meter, Sunnyvale, CA, USA). Stability of FNGL in the prepared gels was tested measuring the concentrations in gels kept at room temperature $\left(22-25^{\circ} \mathrm{C}\right)$ and standard humidity conditions $(16 \%-18 \%)$ after 3,6 , and 12 months and comparing it with the concentrations of freshly prepared gels $(n=3)$. FNGL content was within the acceptable range $(90 \%-110 \%)$ at 3 and 6 months and significantly $(p<0.05)$ decreased at 1 year $(-16$ $\pm 2 \%$ ). Since this information was not available at the time of the permeability studies, all gels were freshly prepared the day before the experiments.

\section{Quantification of Fingolimod Hydrochloride}

FNGL was quantified using a high-performance liquid chromatography (HPLC) method adapted from Andreani et al. (24). FNGL was labeled with the fluorescence agent 9fluorenylmethyl chloroformate (Fmoc-Cl) to ensure high selectivity and enhanced sensitivity. The HPLC system consisted of a Water ${ }^{\circledR} 717_{\text {plus }}$ Auto Sampler, waters 474 scanning fluorescence detector, Hitachi 2100 elite Lachrome pump, Waters Millipore interface module, and the Millennium Software (Version 3.20; Waters Corporation) data handling system. A reversed phase C18 column $\left(250 \times 4.6\right.$ mm Kromasil ${ }^{\mathrm{TM}} 100-5$ C18) was used at $25^{\circ} \mathrm{C}$ equipped with a guard column (Phenomenex ${ }^{\circledR}$ security guard ${ }^{\mathrm{TM}}$, Torrance, CA, USA). The mobile phase consisted of methanol, $70 \mathrm{mM} \mathrm{K}_{2} \mathrm{HPO}_{4}$ buffer $(\mathrm{pH} 9)$ and water $(90: 5: 5 \mathrm{v} / \mathrm{v})$. Flow rate was $1.5 \mathrm{ml} /$ min. Excitation wavelength was $\lambda=263 \mathrm{~nm}$ and emission wave length was $\lambda=316$. Typical retention time was $20 \mathrm{~min}$. Peak height was used to determine FNGL concentration. FNGL HCL standards were prepared in the same vehicle as the receiver solution of Franz Cells (DPBS containing 5\% bovine serum albumin at $\mathrm{pH} 7.00$ ) and subjected to the same extraction and derivatization procedure as the samples. Briefly, $350 \mu \mathrm{L}$ were added with $1.05 \mathrm{~mL}$ (three times the volume of the sample) of acetonitrile to precipitate albumin. The mixture was vortexed (Fisher vortex genie $2^{\mathrm{TM}}$, Bohemia, NY, USA) for $2 \mathrm{~min}$ and centrifuged for $20 \mathrm{~min}$ at $12000 \mathrm{rpm}$ (Beckmen Coulter Allegra X-22Rcentrifuge with F2402 hermetically sealed rotor). One milliliters of supernatant was withdrawn and transferred to a glass tube $\left(\mathrm{VWR}^{\mathrm{TM}}\right.$ International, lime glass disposable tubes $13 \times 100 \mathrm{~mm}$, West Chester, PA, USA). The sample was dried under vacuum and nitrogen gas at a temperature of $50^{\circ} \mathrm{C}$ (PIERCE Reacti-Therm ${ }^{\circledR}$ Heating module; Champaign, IL, USA). Extraction efficiency was $85 \%-$ $90 \%$. After evaporation, the samples were reconstituted with $200 \mu \mathrm{l}$ of dioxane, $200 \mu \mathrm{l}$ of di-potassium hydrogen phosphate, followed by addition of $200 \mu \mathrm{l}$ of the derivative agent $(18 \mathrm{mg}$ Fmoc-Cl dissolved in $5 \mathrm{~mL}$ dioxane). Finally, the resulting solution was filtered through B-D precision glide $\AA$ filter needle with 5 micron filter $(1.1 \mathrm{~mm} \times 40 \mathrm{~mm}$, Mettawa, IL, USA) and $10 \mu \mathrm{l}$ were injected onto the HPLC column. The assay was linear in the range $1-0.005 \mu \mathrm{g} / \mathrm{ml}\left(r^{2} \geq 0.99\right)$, and the lower limit of quantification was $0.005 \mu \mathrm{g} / \mathrm{ml}$. The CV (\%) for inter-day assays at $5 \mathrm{ng} / \mathrm{mL}$ (lowest limit of quantification LLOQ) and $500 \mathrm{ng} / \mathrm{mL}$ was 12.57 and 0.11 , respectively. Since $\mathrm{Fmoc}-\mathrm{Cl}$ is highly light sensitive, all $\mathrm{Fmoc}-\mathrm{Cl}$ standard solutions and samples were always freshly 
prepared and protected from light with aluminum foil or amber colored glassware.

\section{Quantitative Determination of FNGL in Gel Formulations}

All the formulations were evaluated for content of FNGL present in the gel. One hundred milligrams of the gel were accurately weighed in an Eppendorf tube (Celltreat ${ }^{\circledR}, 2 \mathrm{~mL}$ sterile micro centrifuge tube, Shirley, MA, USA) and diluted to $1 \mathrm{ml}$ with HPLC grade methanol. The mixture was vortexmixed and then centrifuged for $25 \mathrm{~min}$ at $12000 \mathrm{RPM}$. The resulting supernatant was diluted 1000 times by taking $100 \mu \mathrm{l}$ and diluting it to $1 \mathrm{ml}$ with methanol thrice. Finally, $100 \mu \mathrm{l}$ of the solution were evaporated under nitrogen gas at $50^{\circ} \mathrm{C}$ and subjected to the same derivation procedure with $\mathrm{Fmoc}-\mathrm{Cl}$ as described in the previous section. The stock solution $(1 \mathrm{mg} /$ $\mathrm{mL}$ ) was prepared by dissolving the accurately weighed quantity of FNGL HCL in methanol. Standard solutions were prepared by diluting the stock solution with methanol. The assay was linear in the range of $1-0.01 \mu \mathrm{g} / \mathrm{mL}\left(r^{2} \geq 0.99\right)$, and the lower limit of quantification was $0.01 \mu \mathrm{g} / \mathrm{ml}$.

\section{In Vitro Permeability Studies Through Cellulose Membrane}

A modified Franz Diffusion Cell Apparatus with a 1-cm² diffusion area was used to perform the in vitro permeation studies. A Spectra/Por ${ }^{\circledR} 7$ (Laguna Hills, CA, USA) regenerated cellulose membrane (60-65 $\mu \mathrm{m}$ thickness; molecular weight cutoff 1000) saturated in Dulbecco's phosphate buffered saline (DPBS) containing $5 \%$ bovine serum albumin (BSA) was sandwiched between the receiving compartment and donor compartments and secured in place with the pinch clamp. The receiving compartment (volume $8 \mathrm{ml}$ ) was filled with DPBS containing 5\% bovine serum albumin ( $\mathrm{pH} 7.00)$. The system was maintained at $37 \pm 0.5^{\circ} \mathrm{C}$ with a water bath circulator (VWR ${ }^{\mathrm{TM}}$ heating circulating bath, Lawrence, KS, USA) and a jacket surrounding the cell. A Teflon ${ }^{\mathrm{TM}}$ coated magnetic bar continuously stirred the receiving medium to avoid diffusion layer effects. A 0.5-g gel sample was placed evenly on the surface of the membrane in the donor compartment that was sealed with aluminum foil and Parafilm ${ }^{\circledR}$ to prevent evaporation. Three hundred fifty microliters of receptor fluid were withdrawn from the receiving compartment at $0.5,1,1.5,2,3,4,8$, and $24 \mathrm{~h}$ and replaced with $350 \mu \mathrm{L}$ of fresh solution. Each sample was processed with the same procedure described for the standards.

\section{Preparation of Excised Dorsal Porcine Ear Skin}

The fresh porcine ear was purchased from a local butcher shop. Excised Dorsal Porcine Ear Skin (EDPES) was immediately cut into pieces with a surface area of approximately $3 \mathrm{~cm} \times 3 \mathrm{~cm}$ with scissors. Then, the skin was separated from the connecting tissues with a surgical scalpel and frozen immediately. Skin was always used within 15 days from the preparation. The thickness of the obtained skin was measured with an electronic digital caliper (Fowler electronic digital calipers, Fernley, NV, USA). It ranged from 0.07 to $0.12 \mathrm{~cm}$. The skin was used immediately after thawing and hydrated in DPBS containing $5 \%$ bovine serum albumin $\mathrm{pH} 7.0$ for $45 \mathrm{~min}$ at room temperature. Integrity of the skin was checked by visual examination and inspection of the cumulative amount versus time profiles to ensure that no holes or other imperfections were present.

\section{In Vitro Permeability Studies through EDPES}

The EDPES was mounted between receiving and donor compartments of the Modified Franz Diffusion cells. The same apparatus and experimental procedure described for permeation study through cellulose membrane was used. The skin was set in place with the stratum corneum facing the donor compartment and the dermal side facing the receptor compartment. The sampling times were the same as the cellulose membrane studies.

\section{Quantification of FNGL in EDPES}

At the end of the experiment $(24 \mathrm{~h})$, the skin was removed from the Franz-cell assembly and the remaining gel was washed away with DPBS containing $5 \%$ bovine serum albumin $\mathrm{pH} 7.00$ followed by gentle patting with paper tissues. In the first set of experiments testing the strength of FNGL, we determined the total skin retention with the following procedures: skin was cut into four pieces and placed in a vial containing $2 \mathrm{~mL}$ methanol and sonicated for $30 \mathrm{~min}$. A magnetic stirrer was placed in the vial and stirred constantly at 500 RPM for $24 \mathrm{~h}$ to allow the methanol to evaporate and ensure complete extraction of FNGL from the skin. At the end of $24 \mathrm{~h}$, the remaining traces of methanol were evaporated under influence of nitrogen gas at $50^{\circ} \mathrm{C}$. The vacuum dried samples were reconstituted, fluorescent labeled, and filtered as described above; $10 \mu \mathrm{l}$ of the resulting solution were injected onto the HPLC. In the experiments testing the effect of Aveeno® strength on the permeability of FNGL base gel, we determined FNGL retention in stratum corneum and in epidermis/dermis using the tape-stripping procedure to remove the stratum corneum. Adhesive tapes (Scotch 3 M Gloss Finish Transparent Tape, Pleasant Prairie, WI, USA) were applied with uniform pressure on the skin surface and then removed. The procedure was repeated for 35 times. FNGL was extracted from the adhesive tapes by immerging the tape in $2 \mathrm{~mL}$ methanol followed by $15 \mathrm{~min}$ of sonication. This solution was then transferred to a new vial and the methanol was evaporated under nitrogen gas at $50^{\circ} \mathrm{C}$. The entire sample was reconstituted with subsequent addition of $2.8 \mathrm{~mL}$ of dioxane, $200 \mu \mathrm{l}$ of di-potassium hydrogen phosphate, followed by addition of $200 \mu \mathrm{l}$ of the Fmoc-Cl. Finally, the resulting solution was filtered through B-D precision glide ${ }^{\circledR}$ filter needle with 5 micron filter $(1.1 \mathrm{~mm} \times 40 \mathrm{~mm}$, Mettawa, IL, USA $) ; 10 \mu 1$ of resulting solution were injected onto the HPLC column. The remaining skin, consisting mostly of epidermis and dermis, was treated with the procedure described above for the whole skin.

\section{Data Analysis}

Data obtained by HPLC analysis have been corrected for sampling effects. Cumulative amount of FNGL collected in the receiver $\left(\mu \mathrm{g} / \mathrm{cm}^{2}\right)$ was plotted as a function of time. The flux value (Jss, $\mu \mathrm{g} / \mathrm{cm}^{2} / \mathrm{h}$ ) for each experiment was obtained from the slope (steady state portion) of the linear portion of 
the data fitted by regression analysis (25). Lag-time $\left(\mathrm{T}_{\mathrm{lag}}\right)$ was determined from the $\mathrm{X}$-intercept of the regression line. The diffusion coefficient was obtained using the formula: $D=L^{2}$ / $6 \times \mathrm{T}_{\text {lag }}$, where $L$ is thickness of the skin. The apparent permeability coefficient $(\mathrm{Kp}, \mathrm{cm} / \mathrm{h})$ was obtained by dividing Jss by the donor concentration $(\mathrm{Cd})$. The partition coefficient $(P$, no unit) was obtained using formula; $P=L \times \mathrm{Kp} / D$. For release data analysis, cumulative permeation $\left(\mu \mathrm{g} / \mathrm{cm}^{2}\right)$ was plotted as a function of square root of time, where linearity is indicative of first order release (25). Release rate was estimated as the slope of such plots $\left(\mu \mathrm{g} / \mathrm{cm}^{2} / \mathrm{t}^{0.5}\right)$. Penetration-enhancing activities were expressed as enhancement ratios (ER), i.e., the ratio of the flux value with enhancer to that obtained without enhancer. Mean, standard deviation (SD), coefficient of variation $(\mathrm{CV} \%)$, percentage error (E \%), ANOVA, and paired $t$ test were calculated with Microsoft Excel 2013 (Microsoft, Seattle, WA, USA).

\section{RESULTS}

\section{In Vitro Permeability Studies}

Figure 2 (top panels) shows the permeation profiles through cellulose membranes. Table I reports Flux (Jss), lagtime, permeability coefficient $(\mathrm{Kp})$, and release rate (RR) calculated from the same studies. Figure 2 (lower panels) shows the permeation profiles through EDPES. Table II reports the corresponding Flux (Jss), enhancement ratio (ER), lag-time, diffusion coefficient $(D)$, partition coefficient $(P)$, permeability coefficient $(\mathrm{Kp})$, and release rate $(\mathrm{RR})$, total skin retention (TR), stratum corneum (SC) retention, and epidermal (E) and dermis (D) retention (ED) of Fingolimod gels from the same studies.

Effect of Strength. The left panels in Fig. 2 show that the permeation profiles exhibit a similar trend through both cellulose and EDPES membranes. The overall permeability was higher when we used cellulose membranes since they offer little resistance to permeation and mostly permit to identify possible negative interactions among the components of a formulation. Specifically, for both membranes, Jss, lag-time, and RR were similar between the gels containing $0.05 \%$ and $0.1 \%$ FNGL $(p>0.18)$ and increased significantly for the $0.5 \%$ and $1 \%$ FNGL gels $(\mathrm{p}<0.01)$. However, no significant difference was observed also between the $0.5 \%$ and $1 \%$ FNGL $(p>0.54)$. For this reason, the $0.5 \%$ FNGL strength was selected as the base gel strength on which the effect of the permeation enhancer was tested.

Effect of Aveeno ${ }^{\circledR}$. Figure 2 right panels show the permeability profiles of FNGL gels added with various concentration of Aveeno®. In the cellulose membrane studies, addition of colloidal oatmeal at $1 \%, 3 \%$, and $6 \%$ did not show any significant effect on the steady state flux of FNGL compared to the control gel ( $0.5 \%$ FNGL). However, the addition of $10 \%$ colloidal oatmeal significantly decrease flux compared to control $(p<0.05)$ probably by increasing the viscosity of the gel formulation. The release profiles of gels followed a matrix diffusion kinetics confirming that FNGL completely dissolves

\section{Cellulose}
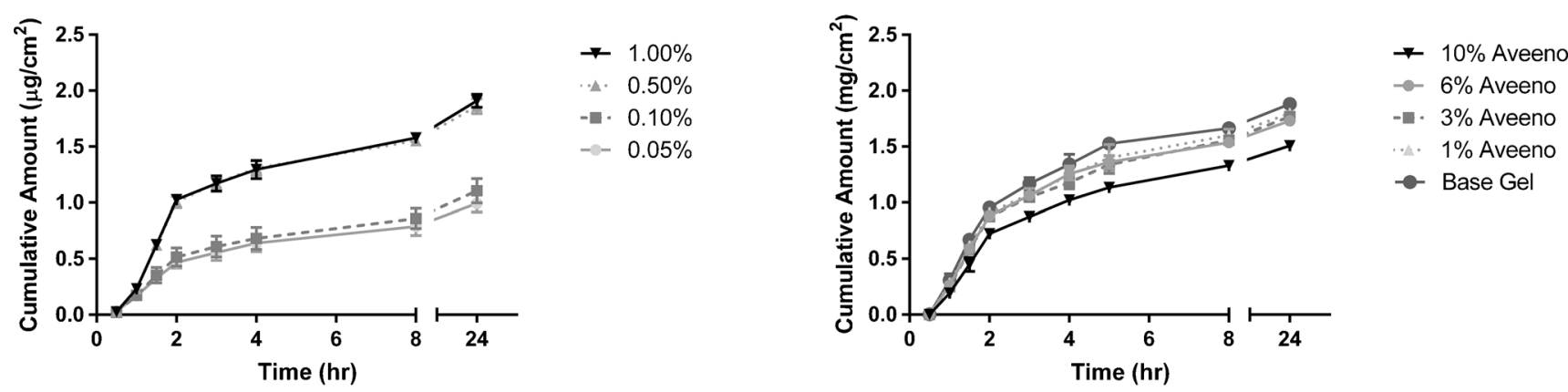

\section{EDPES}
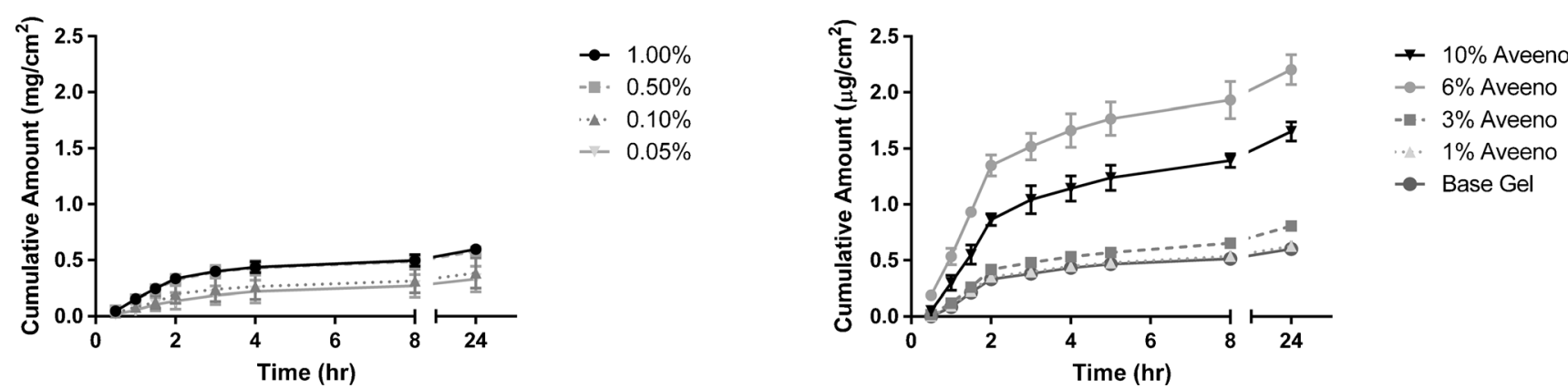

Fig. 2. Permeation profiles: effect of FNGL strength (left) and Aveeno® concentrations (right) on the permeation profiles of FNGL through cellulose membranes (top) and excised porcine dorsal ear skin (bottom). The FNGL 0.5\% strength was selected as the base gel concentration when testing the effect of various concentration of the permeation enhancer Aveeno ${ }^{\circledR}$ 
Table I. Flux (Jss), Lag-time, Permeability Coefficient (Kp), and Release Rate (RR) of Fingolimod Gels Through Cellulose Membrane ( $n=3$ )

\begin{tabular}{llllll}
\hline & Gel & Jss $\left(\mu \mathrm{g} / \mathrm{cm}^{2} / \mathrm{h}\right)$ & Lag-time $(\mathrm{h})$ & $\mathrm{Kpx} 10^{-3}(\mathrm{~cm} / \mathrm{h})$ & $\mathrm{RR}\left(\mu \mathrm{g} / \mathrm{cm}^{2} / \mathrm{h}^{1 / 2}\right)$ \\
\hline Effect of strength & $0.05 \%$ & $0.29 \pm 0.02$ & $0.40 \pm 0.10$ & $1.13 \pm 0.15$ & $0.61 \pm 0.06$ \\
& $0.10 \%$ & $0.33 \pm 0.04$ & $0.44 \pm 0.04$ & $0.71 \pm 0.09$ & $0.69 \pm 0.1$ \\
& $0.50 \%{ }^{\mathrm{a}}$ & $0.66 \pm 0.02$ & $0.53 \pm 0.03$ & $0.26 \pm 0.01$ & $1.38 \pm 0.05$ \\
& $1.00 \%$ & $0.67 \pm 0.02$ & $0.54 \pm 0.03$ & $0.13 \pm 0.005$ & $1.41 \pm 0.04$ \\
Effect of Aveeno $§$ on $0.5 \%$ FNGL gel & Control gel ${ }^{\mathrm{a}}$ & $0.62 \pm 0.03$ & $0.51 \pm 0.03$ & $0.26 \pm 0.006$ & $1.32 \pm 0.03$ \\
& $1 \%$ Aveeno & $0.61 \pm 0.01$ & $0.51 \pm 0.02$ & $0.24 \pm 0.005$ & $1.28 \pm 0.03$ \\
& 3\% Aveeno & $0.59 \pm 0.01$ & $0.52 \pm 0.02$ & $0.23 \pm 0.006$ & $1.24 \pm 0.02$ \\
& $6 \%$ Aveeno & $0.59 \pm 0.01$ & $0.50 \pm 0.04$ & $0.23 \pm 0.005$ & $1.24 \pm 0.02$ \\
& $10 \%$ Aveeno & $0.48 \pm 0.01$ & $0.54 \pm 0.03$ & $0.19 \pm 0.005$ & $1.01 \pm 0.04$ \\
\hline
\end{tabular}

${ }^{a}$ Same gel: data collected in different set of experiments

or suspends in the gel and that the membrane and excipients have no significant effect on the release of the drug. When EDPES was used, the addition of $1 \%$ Aveeno® did not affect steady state flux, whereas the $3 \%, 6 \%$, and $10 \%$ Aveeno® gels showed an increase in permeability parameters $(p<0.001)$, although not in a linear way, with the $6 \%$ gel displaying the highest effects (Fig. 2). The $10 \%$ Aveeno ${ }^{\circledR}$ gel significantly reduced the steady state flux compared to the $6 \%$ colloidal oatmeal preparation although it was still higher than that observed for the $3 \%$ and $1 \%$ gels. In conclusion, the enhancement ratio (ER, Table II) was maximum with addition of Aveeno ${ }^{\circledR}$ at the $6 \%$ level.

\section{Quantification of FNGL in EDPES}

Table II also reports the results for the skin retention studies. The total amount of FNGL retained in the skin (TR) showed a trend similar to that observed for permeability parameters, with the $0.05 \%$ and $0.10 \%$ strength gels and the $0.50 \%$ and $1.00 \%$ gels having similar retention data. The addition of Aveeno ${ }^{\circledR}$ significantly decreased the total amount retained (TR) in the skin at the 3\%,6\%, and $10 \%$ level, with a minimum for the $6 \%$ gel. Specifically, the amount retained by the stratum corneum decreased similarly in all the gels containing Aveeno ${ }^{\circledR}$, whereas the amount retained by the epidermis and dermis (ED) reached a minimum for the $6 \%$ gel (Table II). In summary, addition of colloidal oatmeal at the $6 \%$ level significantly increased FNGL flux across EDPES compared to the other gels, whereas the corresponding skin retention was significantly lower.

\section{DISCUSSION}

The present investigation explores the possibility to deliver therapeutically relevant amounts of FNGL to the skin with a gel formulation. We selected hydroxypropyl cellulose as a gelling agent because the solubilization of FNGL requires a substantial portion of organic solvent (ethanol). Indeed, although Fingolimod hydrochloride powder is freely soluble in water, Fingolimod is a base $(\mathrm{pKa}=7.82)$, and its solubility decreases with increasing $\mathrm{pH}$ (e.g. $<0.01 \mathrm{mg} / \mathrm{mL}$ at $\mathrm{pH} 6.8$ (26)). The free base has a high partition coefficient ( $\log \mathrm{P}$,
4.06), and it is very soluble in organic solvents (10). Therefore, FNGL.HCL was dissolved in a mixed solvent (ethanol/water) where the proportion of ethanol was kept constant at $20 \%$ w/w, whereas water was adjusted qs to final weight. In addition, ethanol improves the appearance and spreadability of the gel and has its own penetration-enhancing properties (27). No precipitation or cloudiness was observed in the obtained gels even at the highest strength (1.0\% FNGL.HCL). The gels containing Aveeno ${ }^{\circledR}$ were opaque as expected because of the presence of colloidal particles. The gels, however, maintained a consistent appearance with time.

The poor solubility of fingolimod in water at physiological $\mathrm{pH}$ presented a challenge to the selection of the solution for the receiver compartment of the Franz-cell apparatus. We preferred to maintain this solution similar to the physiological condition of the skin and avoid the use of organic solvents and surfactants. For this reason, we selected DPBS ( $\mathrm{pH} 7.0$ ) added with 5\% albumin as the receiving solution. Fingolimod has high affinity for albumin and in plasma is more than $99.7 \%$ bound mainly to albumin (26). The solubility of FNGL.HCL in DPBS containing $5 \%$ BSA is higher than $0.2 \mathrm{mg} / \mathrm{mL}$ that is the concentration of the stock solution we prepared by dissolving $10 \mathrm{mg}$ of FNGL.HCL in $50 \mathrm{~mL}$ of solvent. The solution was obtained by adding the solvent in small aliquots of 5 to $10 \mathrm{~mL}$ each and vortex mixed after each addition. Adding all the solvent at once resulted in precipitation. The solution was stable and clear when stored in the refrigerator $\left(4^{\circ} \mathrm{C}\right)$ for at least 3 weeks.

The aim of the first set of experiments was to find the optimal strength for the gel. The effective skin concentration that is necessary for the treatment of TLDISD is currently unknown; therefore, a series of gels of increasing, albeit arbitrarily chosen, strength was tested, where the maximum strength of the range was determined by the solubility of FNGL.HCL in the solvent mixture selected. The results of these experiments showed that there was not a significant difference on the overall permeability parameters between the gels containing $0.50 \%$ and the $1.00 \%$ FNGL HCL, when either the cellulose membrane or the EDPES were used. It is possible that, at the highest strength, FNGL precipitates in the formulation when the gel gets in contact with the hydrated cellulose membrane or the EDPES. Another possibility is that at the higher concentration, the amount of FNGL penetrated exceeded its solubility in DPBS in BSA (5\%). However, as previously reported, solubility of FNGL in such solvent was at 


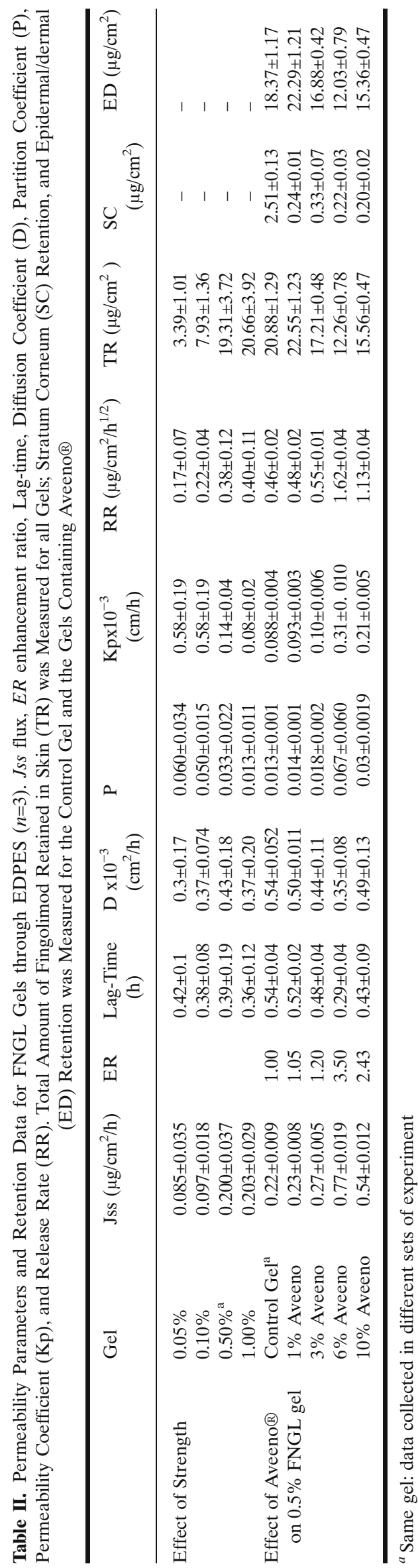

least $0.2 \mathrm{mg} / \mathrm{mL}$, whereas the maximum concentrations at $24 \mathrm{~h}$ observed in the permeability studies were in the $0.51-1.93 \mu \mathrm{g}$ range. Therefore, the $0.50 \%$ FNGL.HCL gel was selected as the base gel to investigate the effect of Aveeno ${ }^{\circledR}$ as penetration enhancer. The addition of permeation-enhancing compounds to topical drug delivery systems may improve the penetration of drugs by modifying the thermodynamic activity of penetrant (e.g., changes in partitioning tendencies) or by altering skin barrier properties (e.g., changes in the fluidity of extracellular fluids) (28). However, many commonly used penetration enhancers have also disadvantages mainly when added to formulations meant to treat skin condition such as AD. For example, Transcutol ${ }^{\circledR}$ may cause drying of skin by leaching fats (29). Oleic acid is known to increase transepidermal water loss (TEWL) and also cause disruption of stratum corneum lipids $(30,31)$, which is very undesirable in pathological condition like eczema, where skin barrier function is already compromised. Topical menthol treatments can cause skin irritation, rashes, or allergic reactions. Camphor can enter the body quickly throughout broken skin and reach concentrations that are high enough to cause poisoning $(32,33)$. Because of the disadvantages mentioned above, we selected colloidal oatmeal (Aveeno®) as penetration enhancer because of its gentle action and possible synergistic effects with FNGL (22). Colloidal oatmeal is a fine powder obtained from grinding oat kernels until no more than $3 \%$ of the particles exceed $150 \mu \mathrm{m}$ (19). Being a natural product, it is a mixture of several components, such as polysaccharides $(65 \%-85 \%)$, proteins $(15 \%-$ $20 \%$ ), lipids ( $3 \%-11 \%)$, fibers (5\%), and $\beta$-glucans (5\%) (19). It also contains small amounts of enzymes, vitamins (A, B, and E), saponins, and antioxidants (flavonoids and avenanthramides) (23). All the components contribute to the beneficial effects observed in the skin (19), and some of them have penetration-enhancing properties. For example, proteins and polysaccharides absorb water and form a hydrophylic film on the surface of the skin that contributes to moisturize the stratum corneum. The moisturizing effect is usually associated with improved barrier properties for patients with dry skin, whereas SC hydration has been shown to improve transdermal and topical delivery of medicaments (21). Saponins are glycosides surfactants with a great potential as percutaneous permeation enhancers (20). The lipid components of colloidal oatmeal contain oleic, linoleic, and linolenic acids (34), which are beneficial to the skin because they occur naturally in the stratum corneum. These fatty acids are effective penetration enhancers as well (21). Therefore, the overall permeability-enhancing mechanism of colloidal oatmeal is likely due to a combination of effects which may also result in reduced side effects. Aveeno ${ }^{\circledR}$ is approved by the USFDA at concentration up to $10 \%$ and is included in many commercially available formulations meant to treat atopic eczema. Therefore, the presence of colloidal oatmeal may provide additional beneficial effects as well as an improved penetration of FNGL throughout the stratum corneum. Since the presence of a penetration enhancer may also change the thermodynamic activity of the drug (FNGL) in the vehicle and consequently alter its permeability, the formulations containing Aveeno ${ }^{\circledR}$ were first evaluated on cellulose 
membrane to detect possible negative interaction between the base gel and the colloidal oatmeal (28). A synthetic membrane acts mostly as a support for the formulation without affecting the release rate; thus, it is ideal to study the plain formulation release and reproducibility (35). Figure 2 shows that the presence of $1 \%, 3 \%$, or $6 \%$ colloidal oatmeal did not have a negative effect on the release of FNGL from cellulose membrane, whereas the $10 \%$ gel release was lower probably due to the higher viscosity. When the effects of colloidal oatmeal were tested on EDPES as a barrier, the $6 \%$ formulation exhibited the maximum flux enhancement ratio $(\mathrm{ER}=3.5)$ compared to the base gel. On the contrary, for the same formulation, the total amount retained in the skin at the end of the experiments significantly decreased by almost $50 \%$. The tape-stripping technique permits distinguishability between the amount retained in the SC and in the epidermis/dermis (ED). Inspection of these data shows that the presence of Aveeno ${ }^{\circledR}$ decreased the amount retained by the $\mathrm{SC}$ to a similar extent across all the Aveeno ${ }^{\circledR}$ gels suggesting that this process is independent of colloidal oatmeal concentration in the range tested. Conversely, the amount retained in the ED was not affected at the $1 \%$ level and decreased for the $3 \%$, $6 \%$, and $10 \%$ gels with a maximum decrease at the $6 \%$ level. This data suggests that colloidal oatmeal facilitates the release of FNGL out of the SC and ED. At the lowest level (1\%), this phenomenon occurs only for the SC, whereas retention by the ED is still similar to the base gel. As the concentration of colloidal oatmeal increases, release of FNGL from the ED also increases with a minimum retention for the $6 \%$ gel. The EDPES experiments confirm the cellulose membrane finding that increasing the Aveeno ${ }^{\circledR}$ strength to $10 \%$ does not improve FNGL permeability. In conclusion, the presence of colloidal oatmeal increases FNGL permeability across the skin; however, it decreases retention by the skin (Table II). Whether this has positive or negative consequences on the therapeutic effects of FNGL can be determined only with in vivo studies. Preliminary studies in an animal model of Atopic Dermatitis showed that the prepared gels were indeed successful in reducing biomarkers of inflammation $(36,37)$. The complete in vivo study will be presented in a forthcoming scientific communication.

\section{CONCLUSIONS}

In conclusion, a series of FNGL·HCL, 2\% hydroxypropyl cellulose gels was successfully prepared and tested in vitro for permeability and retention properties. The gel containing $0.50 \%$ Fingolimod hydrochloride showed optimal in vitro permeability and retention properties. The addition of colloidal oatmeal significantly improved overall permeability at the $6 \%$ concentration showing that colloidal oatmeal may have penetration-enhancing properties.

\section{ACKNOWLEDGMENTS}

These studies were supported by the Division of Pharmaceutical Science, Long Island University, Brooklyn Campus NY.

\section{Compliance with Ethical Standards}

Conflict of Interest The authors declare that they have no competing interests.

\section{REFERENCES}

1. Herzinger T, Kleuser B, Schafer-Korting M, Korting HC. Sphingosine-1-phosphate signaling and the skin. Am J Clin Dermatol. 2007;8(6):329-36.

2. Leung DY, Boguniewicz M, Howell MD, Nomura I, Hamid QA. New insights into atopic dermatitis. J Clin Invest. 2004;113(5):651-7.

3. Cather J, Menter A. Novel therapies for psoriasis. Am J Clin Dermatol. 2002;3(3):159-73.

4. Norris DA. Mechanisms of action of topical therapies and the rationale for combination therapy. J Am Acad Dermatol. 2005;53(1 Suppl 1):S17-25.

5. Pardasani AG, Feldman SR, Clark AR. Treatment of psoriasis: an algorithm-based approach for primary care physicians. Am Fam Physician. 2000;61(3):725-33. 36.

6. Callen J, Chamlin S, Eichenfield LF, Ellis C, Girardi M, Goldfarb $\mathrm{M}$, et al. A systematic review of the safety of topical therapies for atopic dermatitis. Br J Dermatol. 2007;156(2):203-21.

7. Charman CR, Morris AD, Williams HC. Topical corticosteroid phobia in patients with atopic eczema. Br J Dermatol. 2000;142(5):931-6.

8. Cai Y, Fleming C, Yan J. New insights of T cells in the pathogenesis of psoriasis. Cell Mol Immunol. 2012;9(4):302-9.

9. Pasparakis M, Haase I, Nestle FO. Mechanisms regulating skin immunity and inflammation. Nat Rev Immunol. 2014;14(5):289-301.

10. Brinkmann V, Billich A, Baumruker T, Heining P, Schmouder R, Francis G, et al. Fingolimod (FTY720): discovery and development of an oral drug to treat multiple sclerosis. Nat Rev Drug Discov. 2010;9(11):883-97.

11. Reines I, Kietzmann M, Mischke R, Tschernig T, Luth A, Kleuser $\mathrm{B}$, et al. Topical application of sphingosine-1-phosphate and FTY720 attenuate allergic contact dermatitis reaction through inhibition of dendritic cell migration. J Investig Dermatol. 2009;129(8):1954-62.

12. Gollmann G, Neuwirt H, Tripp CH, Mueller H, Konwalinka G, Heufler C, et al. Sphingosine-1-phosphate receptor type-1 agonism impairs blood dendritic cell chemotaxis and skin dendritic cell migration to lymph nodes under inflammatory conditions. Int Immunol. 2008;20(7):911-23.

13. Forrest M, Sun SY, Hajdu R, Bergstrom J, Card D, Doherty G, et al. Immune cell regulation and cardiovascular effects of sphingosine 1-phosphate receptor agonists in rodents are mediated via distinct receptor subtypes. J Pharmacol Exp Ther. 2004;309(2):758-68.

14. Sanna MG, Liao J, Jo E, Alfonso C, Ahn MY, Peterson MS, et al. Sphingosine 1-phosphate (S1P) receptor subtypes S1P1 and S1P3, respectively, regulate lymphocyte recirculation and heart rate. J Biol Chem. 2004;279(14):13839-48.

15. Schaper K, Dickhaut J, Japtok L, Kietzmann M, Mischke R, Kleuser B, et al. Sphingosine-1-phosphate exhibits antiproliferative and anti-inflammatory effects in mouse models of psoriasis. J Dermatol Sci. 2013;71(1):29-36.

16. Nakashima D, Kabashima K, Sakabe J, Sugita K, Kobayashi T, Yoshiki R, et al. Impaired initiation of contact hypersensitivity by FTY720. J Investig Dermatol. 2008;128(12):2833-41.

17. Chadha G, Sathigari S, Parsons DL, Jayachandra Babu R. In vitro percutaneous absorption of genistein from topical gels through human skin. Drug Dev Ind Pharm. 2011;37(5):498-505.

18. Cerio R, Dohil M, Jeanine D, Magina S, Mahe E, Stratigos AJ. Mechanism of action and clinical benefits of colloidal oatmeal for dermatologic practice. J Drugs Dermatol. 2010;9(9):1116-20.

19. Reynertson KA, Garay M, Nebus J, Chon S, Kaur S, Mahmood K, et al. Anti-inflammatory activities of colloidal oatmeal (Avena sativa) contribute to the effectiveness of oats in treatment of itch associated with dry, irritated skin. J Drugs Dermatol. 2015;14(1):43-8. 
20. Sapra B, Jain S, Tiwary AK. Effect of Asparagus racemosus extract on transdermal delivery of carvedilol: a mechanistic study. AAPS PharmSciTech. 2009;10(1):199-210.

21. Williams AC, Barry BW. Penetration enhancers. Adv Drug Deliv Rev. 2004;56(5):603-18.

22. Fowler Jr JF. Colloidal oatmeal formulations and the treatment of atopic dermatitis. J Drugs Dermatol. 2015;13(10):1180-3. quiz 4-5.

23. Kurtz ES, Wallo W. Colloidal oatmeal: history, chemistry and clinical properties. J Drugs Dermatol. 2007;6(2):167-70.

24. Andreani P, Graler MH. Comparative quantification of sphingolipids and analogs in biological samples by highperformance liquid chromatography after chloroform extraction. Anal Biochem. 2006;358(2):239-46.

25. Higuchi WI. Analysis of data on the medicament release from ointments. J Pharm Sci. 1962;51:802-4.

26. Lai J, Parepally J, Men A. Clinical Pharmacology and Biopharmaceutics Review (Fingolimod) Washington, DC: CDER; 2010 [cited 2015 8/24]. Review]. Available from: http:// www.accessdata.fda.gov/drugsatfda_docs/nda/2010/ 022527orig1s000clinpharmr.pdf.

27. Kobayashi D, Matsuzawa T, Sugibayashi K, Morimoto Y, Kimura M. Analysis of the combined effect of 1-menthol and ethanol as skin permeation enhancers based on a two-layer skin model. Pharm Res. 1994;11(1):96-103.

28. Jantharaprapap R, Stagni G. Effects of penetration enhancers on in vitro permeability of meloxicam gels. Int J Pharm. 2007;343(12):26-33.

29. Westerholm E, Schenk L. Comparative analysis of toxicological evaluations for dermal exposure performed under two different EU regulatory frameworks. Regul Toxicol Pharmacol. 2014;68(1):51-8.

30. Tanojo H, Boelsma E, Junginger HE, Ponec M, Bodde HE. In vivo human skin permeability enhancement by oleic acid: a laser Doppler velocimetry study. J Control Release. 1999;58(1):97-104.

31. Penzes T, Blazso G, Aigner Z, Falkay G, Eros I. Topical absorption of piroxicam from organogels - in vitro and in vivo correlations. Int J Pharm. 2005;298(1):47-54.

32. Ahad A, Aqil M, Kohli K, Sultana Y, Mujeeb M, Ali A. Interactions between novel terpenes and main components of rat and human skin: mechanistic view for transdermal delivery of propranolol hydrochloride. Curr Drug Deliv. 2011;8(2):21324.

33. Tokuoka Y, Suzuki M, Ohsawa Y, Ochiai A, Ishizuka M, Kawashima N. Enhancement in skin permeation of 5aminolevulinic acid using 1-menthol and its derivatives. Drug Dev Ind Pharm. 2008;34(6):595-601.

34. Zhou M, Robards K, Glennie-Holmes M, Helliwell S. Oat lipids. J Am Oil Chem Soc. 1999;76(2):159-69.

35. Guidance for Industry: Nonsterile Semisolid Dosage Forms: Scale-Up and Postapproval Changes: Chemistry, Manufacturing, and Controls; In Vitro Release Testing and In Vivo Bioequivalence Documentation, in Food and Drug Administration Center for Drug Evaluation Research. 1997, FDA: Rockville, MD.

36. Tamakuwala M, Stagni G. To evaluate in vivo anti-atopic efficacy of optimized fingolimod hydrochloride topical gel in DNCB induced hairless mouse model using EASI intensity index score. Poster presentation at the 2014 AAPS Annual Meeting and Exposition; November 2-6, 2014; San Diego, CA 2014;Poster W4255.

37. Tamakuwala M, Stagni G. Fingolimod hydrochloride topical gels reduces inflammation in an animal model of atopic dermatitis. Poster presentation at the 2014 AAPS Annual Meeting and Exposition; November 2-6, 2014; San Diego, CA; 2014;T2132. 